\title{
Subcutaneous ketamine prolongs the analgesic effect of local infiltration of plain Bupivacaine in children undergoing inguinal herniotomy
}

\author{
Alex Oham ${ }^{1}$, Ifeoma Ekwere ${ }^{1}$, Kingsley Tobi ${ }^{1,2}$
}

1. University of Benin Teaching Hospital, Anaesthesiology.

2. University of Namibia, Department of Surgery and Anaesthesiology.

\begin{abstract}
Background: Inguinal herniotomy is one of the commonest paediatric surgical procedures at the University of Benin Teaching Hospital. Incisional infiltration with plain bupivacaine has been used to provide postoperative analgesia for this procedure but with a short duration of action, 4- 6hours.

Aims/Objectives: The aim of this study therefore was to evaluate the efficacy of subcutaneous ketamine on post-operative analgesia in children undergoing unilateral inguinal herniotomy

Methods: Forty-six (46) ASA I or II patients aged three to seven years scheduled for unilateral inguinal herniotomy were recruited. The patients were randomized to receive surgical wound site infiltration with plain bupivacaine plus subcutaneous injection of ketamine for group I or surgical wound site infiltration plain bupivacaine plus $2 \mathrm{ml}$ of saline subcutaneously for group II at the end of surgery. Data obtained were analyzed using SPSS version 20. Continuous data were compared using student t-test while categorical data were compared using Chi-square or Fisher's exact test. P- value $<0.05$ was considered statistically significant.

Results: In group, I, the mean time to first analgesic request was 667.7 minutes (11.12hours) and in group II, it was 371.3minutes $(6.2$ hours) with $\mathrm{p}<0.001$. The pain scores were better and more favourable in group I from the 8th hour and above of the assessment period. The mean post-operative analgesic consumption in 24 hours was less in group I (19.35 $\pm 5.4 \mathrm{mg})$ than in group II $(27.32 \pm 5.8 \mathrm{mg})$ with p-value $<0.001$.

Conclusion: The study showed that subcutaneous ketamine prolonged the analgesic effect of plain bupivacaine surgical wound site infiltration in children undergoing unilateral inguinal herniotomy.

Keywords: Subcutaneous ketamine, inguinal herniotomy, children, postoperative analgesia.

DOI: https://doi.org/10.4314/ahs.v20i2.34

Cite as: Oham A, Ekwere I, Tobi K. Subcutaneous ketamine prolongs the analgesic effect of local infiltration of plain Bupivacaine in children undergoing inguinal herniotomy. Afri Health Sci. 2020; 20(2): 806-814. https:// doi.org/ 10.4314/ abs.v20i2.34
\end{abstract}

\section{Introduction}

Inguinal herniotomy is a common surgical procedure in the paediatric age group ${ }^{1}$. Postoperative pain is a major problem following this procedure, thus adequate and safe post-operative pain control is necessary for a comfortable postoperative period and early discharge. In addition, good management of post-operative pain relieves suffering and leads to earlier mobilization, shorter hospital stay, lesser cost of care and also increases patient satisfaction

\section{Corresponding author: \\ Kingsley Tobi, \\ University of Benin Teaching \\ Hospital, Anaesthesiology; \\ University of Namibia, Department of \\ Surgery and Anaesthesiology \\ Email: tobikingsley@yahoo.com}

Wound infiltration with local anaesthetics (LA) is a safe, simple and effective method of post- operative pain management ${ }^{2}$. The use of local anaesthetic infiltration after minor surgical procedures like inguinal herniotomy has been shown to reduce post-operative opioid requirement and thereby a reduction in the side effects of opioid such as respiratory depression, nausea and vomiting ${ }^{3}$. However, it has one major drawback which is the short duration of analgesia between 4-6 hours. ${ }^{4}$

Ketamine is a well-known general anaesthetic agent which in low dose acts as an analgesic ${ }^{5}$. The use of ketamine as an anaesthetic agent dates back to four to five decades. It is a non- competitive N-Methyl- D-Aspartate (NMDA) receptor antagonist. It's binding to the NMDA receptor decreases pain by interfering with pain transmission ${ }^{6}$.

Low dose ketamine of $0.1-0.5 \mathrm{mg} / \mathrm{kg}$ intravenously is associated with less adverse effect and is well tolerated 
by patients ${ }^{6}$. It also produces opioid-sparing effect after a painful ambulatory surgery such as inguinal herniotomy. ${ }^{6}$ However, there is limited literature on the use of low dose subcutaneous ketamine plus plain bupivacaine surgical site wound infiltration for postoperative analgesia in our environment. In addition, subcutaneous ketamine has the advantage of slow and sustained release with the potential of prolonging its analgesic effect. This study thus sought to determine the effect of subcutaneous ketamine on bupivacaine wound infiltration on postoperative pain relief following inguinal herniotomy in children.

\section{Hypothesis}

Null hypothesis: There is no difference in effectiveness and duration of analgesia between subcutaneous ketamine plus plain bupivacaine infiltration alone.

Alternate hypothesis: There is a difference in effectiveness and duration of analgesia between subcutaneous ketamine injection plus plain bupivacaine infiltration and plain bupivacaine infiltration alone.

\section{Patients and methods}

This was a prospective, randomized comparative double-blind study. The patients/parents and the investigator were blinded to the study drugs.

This study was carried out at the University of Benin Teaching Hospital, Benin City, Edo state after obtaining ethical clearance from the Hospital's Ethics Committee. At the study Centre (UBTH), about 8-10 herniotomies are performed weekly and evenly distributed among four consultant Paediatric surgeons.

Informed consent was obtained from the parents/ guardians of patients aged 3-7 years in ASA class 1 or 2 scheduled for herniotomy under general anaesthesia. This study took approximately 11 weeks to complete. (from January to April 2016)

The sample size was calculated using a formula and putting into consideration outcome of a previous study.

Inclusion criteria included ASA 1 or 11 patients aged from 3-7 years scheduled for herniotomy under general anaesthesia.

On the other hand, exclusion criteria included the following, Parent's or guardian's refusal, Patient's known to be allergic to bupivacaine and other amide local anaesthetic agents, allergy to ketamine, bilateral herniotomy, patients with seizure disorder and patients with cardiac disease.

Preoperative patients review was carried out in the ward the day before surgery to ascertain patient's fitness for anaesthesia following admission into the ward. Preoperative history was taken which included the presence of respiratory tract infections, previous surgery and anaesthesia taking note of untoward events and history of sickle cell anaemia in the family.

Detailed general examination, respiratory and cardiovascular system examinations were done.

Routine investigations such as full blood count (FBC), electrolyte urea creatinine and urinalysis were done. American Society of Anaesthesiologist (ASA) fasting guideline was explained to the parent/guardian, and the patient was fasted accordingly. Written informed consent was obtained from parent/guardian of every eligible patient after the procedure was clearly explained to the understanding of the parent/guardian. The procedure was also explained to the understanding of older children. All the patients were given oral promethazine at a dose of $0.5 \mathrm{mg} / \mathrm{kg}$ a night before the surgery and on the morning of surgery as per departmental protocol to reduce separation anxiety which is a problem in this age group.

Patients' randomization was achieved by randomly assigning 46 patients into two equal groups of 23 each using a random number table with an allocation ratio of 1:1. The serial number and group allocations were packed in a sealed and opaque envelope. The allocation sequence was concealed from the principal investigator enrolling and assessing the participants. Only the serial number was entered on the proforma sheet of the individual patients. The sealed papers were put in the same envelope with the proforma and stapled back. These were reopened at the conclusion of the study. Each patient or parent/guardian was asked to pick one envelop after thoroughly shaking the bag. Group I received subcutaneous $0.5 \mathrm{mg} / \mathrm{kg}$ ketamine and local infiltration of bupivacaine while group II received local infiltration of bupivacaine and subcutaneous saline.

In the theatre, the anaesthetic machine, laryngoscopes, endotracheal tubes, stylet, laryngeal mask airway, face mask and resuscitation drugs like atropine, adrenaline was checked and made available. A precordial stethoscope was attached to monitor the heart sounds and breath sounds.

A multiparameter monitor (EDAN $\left.{ }^{\circledR}\right)$ was attached to the patient and baseline pulse rate, non-invasive blood pressure (NIBP), oxygen saturation (SpO2), electrocardiogram (ECG) and body temperature were obtained and recorded. Anaesthesia was induced using a step- 
wise increase of halothane from $0.5 \%$ to $3.5 \%$ in $100 \%$ oxygen via appropriately sized face mask attached to a Jackson Rees modification of Ayres T- piece or Bain's circuit if the weight of the patient was more than $25 \mathrm{~kg}$. Intravenous access was established with size $22 \mathrm{G}$ cannula and connected to $0.9 \%$ saline. Following adequate depth of anaesthesia, appropriate sized laryngeal mask airway was inserted via which anaesthesia was maintained using isoflurane 1 to $2.5 \%$ in $100 \%$ oxygen.

Analgesia was supplemented using intravenous paracetamol $15 \mathrm{mg} / \mathrm{kg}$ and surgical site skin infiltration with $0.25 \%$ plain bupivacaine $(0.5 \mathrm{mg} / \mathrm{kg})$ by the surgeon prior to skin incision.

Intraoperatively, the pulse rate, blood pressure, oxygen saturation, temperature and ECG were monitored continuously and documented every 5 minutes. Intravenous fluid was maintained with $0.9 \%$ saline at $10 \mathrm{ml} /$ $\mathrm{kg}$ the first hour and $5 \mathrm{ml} / \mathrm{kg}$ subsequently. Another anaesthetist prepared the study drugs in identical syringes and coded them accordingly. The investigator administered the study drugs in the theatre and assessed the pain score and haemodynamic variables in the Post Anaesthetic Care Unit (PACU). At the end of surgery, patients in Group I were injected subcutaneously on the thigh by the investigator with the drug (ketamine $1 \mathrm{mg} /$ $\mathrm{kg}$ made up to $2 \mathrm{ml}$ with $0.9 \%$ saline) prepared by the assistant. Also, the surgical wound site was re-infiltrated with $0.25 \%$ plain bupivacaine $(1 \mathrm{mg} / \mathrm{kg})$ by the surgeon. The oropharynx was then suctioned, and anaesthetic agents were turned off. The laryngeal mask airway was deflated and removed when the patient was fully awake. The patient was given $100 \%$ oxygen via a face mask for 5-10 minutes before being transported to the recovery room/PACU. Also, the patients in group II received the same type of anaesthesia, analgesia and monitoring as those in group I. At the end of surgery, the surgical wound site was also re-infiltrated with $0.25 \%$ of plain bupivacaine $(1 \mathrm{mg} / \mathrm{kg})$ and $2 \mathrm{ml}$ of $0.9 \%$ saline injected subcutaneously on the thigh. The laryngeal mask airway was also removed as in the group 1. They also received oxygen and then transferred to the recovery room like the group 1 patients.

In the post anaesthesia care unit (PACU), the pain score was assessed using the Objective Pain Scale (OPS) every
15 minutes for the first 30 minutes by the investigator. The patient was transferred to the ward when haemodynamically stable. Pain assessment was continued in the ward at 1, 2, 4, 6, 8, 12 and 24 hours. The OPS assesses pain severity with a minimum score of 0 (no pain) and a maximum score of 10 (extreme pain). The scale is made of 5 items and each scored 0,1 or 2. (Appendix 2) Also, the respiratory rate, pulse rate and blood pressure were measured and recorded. Side effects like sedation, nausea, vomiting were noted and recorded as present or absent.

Postoperatively, intravenous pentazocine $0.5 \mathrm{mg} / \mathrm{kg}$ was used for analgesia when pain score was 5 and above in children that could report pain and 4 and above in children who could not report pain as per paediatric surgery protocol.

Socio-demographic data, time of study drug administration, time to first analgesic request, total analgesic consumption, pain scores, complications, hemodynamic variables were recorded using a structured questionnaire.

Data were analysed using the Statistical Package for the Social Sciences (SPSS) version 20.0.

Parametric data were presented as means with standard deviation (SD) and categorical data presented as counts and percentages. Continuous data like age, weight, duration of analgesia and total analgesia consumed were analyzed using independent student's T-test. Categorical variables were analyzed using the chi-square test or Fisher's exact test. A p-value less than 0.05 was considered significant.

\section{Results}

Forty-six (46) ASA I and II patients aged three to seven years were recruited and studied. All the data obtained were analyzed as no patient was lost to protocol violation. The two groups were similar with regard to age, body weight, sex and ASA physical status as shown in Table 1 when compared with (Fisher's exact test). Table I also showed the mean duration of surgery in the two groups, $45.82 \pm 4.5$ minutes for group I and $42.27 \pm 3.5$ minutes for group II and there was a significant difference with P-value of 0.005 \{Students $t$ test\}. The duration of anaesthesia was similar in both groups with no statistically significant difference $(\mathrm{P}=0.15)$ when compared using student's t-test. 
Table I: Patient's characteristics/ duration of surgery and anaesthesia.

\begin{tabular}{|c|c|c|c|c|}
\hline \multirow[b]{2}{*}{ Parameter } & \multicolumn{2}{|c|}{ Study groups (mean $\pm \mathrm{SD}$ ) } & \multirow[b]{2}{*}{$\begin{array}{l}\text { p- } \\
\text { value }\end{array}$} & \multirow{2}{*}{$\begin{array}{l}\text { Level of } \\
\text { significance }\end{array}$} \\
\hline & Group I $(n=23)$ & Group $11(n=23)$ & & \\
\hline Age (years) $)^{x x}$ & $3.45 \pm 0.67$ & $3.68 \pm 1.09$ & 0.408 & NS \\
\hline Body & $14.43 \pm 2.81$ & $15.15 \pm 2.16$ & 0.351 & NS \\
\hline \multicolumn{5}{|l|}{ weight $(\mathrm{kg})^{\mathrm{xx}}$} \\
\hline ASAI/ASAII $(\%)^{x}$ & $12(54.5) / 10(45.5)$ & $12(54.5) / 10(45.5)$ & $>0.999$ & NS \\
\hline Male/Female ${ }^{x}$ & $22 / 0$ & $22 / 0$ & 1.000 & NS \\
\hline Duration & $45.82 \pm 4.47$ & $42.27 \pm 3.47$ & 0.005 & S \\
\hline \multicolumn{5}{|l|}{$\operatorname{surg}(\operatorname{mins})^{x x}$} \\
\hline Duration & $53.87 \pm 4.02$ & $55.48 \pm 4.71$ & 0.150 & NS \\
\hline Anaesth(minus) $)^{\mathrm{xx}}$ & & & & \\
\hline
\end{tabular}

Table II: Baseline vital signs of the patients

\begin{tabular}{|c|c|c|c|c|}
\hline \multirow[b]{2}{*}{ Parameter } & \multicolumn{2}{|c|}{ Study groups (mean \pm SD) } & \multirow[b]{2}{*}{ p-value } & \multirow{2}{*}{$\begin{array}{l}\text { Level of } \\
\text { significance }\end{array}$} \\
\hline & $\begin{array}{l}\text { Group I } \\
(\mathrm{n}=\mathbf{2 3})\end{array}$ & $\begin{array}{l}\text { Group } 11 \\
(\mathrm{n}=23)\end{array}$ & & \\
\hline \multirow[t]{2}{*}{ Pulse rate (bpm) } & 109.78 & $111.82 \pm 8.51$ & 0.491 & NS \\
\hline & 10.65 & & & \\
\hline Systolic blood pressure (mmHg) & $89.64 \pm 3.94$ & $91.86 \pm 4.19$ & 0.076 & NS \\
\hline Diastolic blood pressure (mmHg) & $49.73 \pm 5.23$ & $52.05 \pm 3.14$ & 0.082 & NS \\
\hline \multirow{2}{*}{$\begin{array}{l}\text { Mean arterial pressure }(\mathrm{mmHg}) \\
\mathrm{SpO}_{2}(\%)\end{array}$} & $63.03 \pm 3.83$ & $65.32 \pm 3.16$ & 0.036 & S \\
\hline & $98.55 \pm 0.18$ & $98.90 \pm 0.31$ & 0.180 & NS \\
\hline
\end{tabular}

Student's t-test. 
Table III: Comparison of the OPS of bothGroups

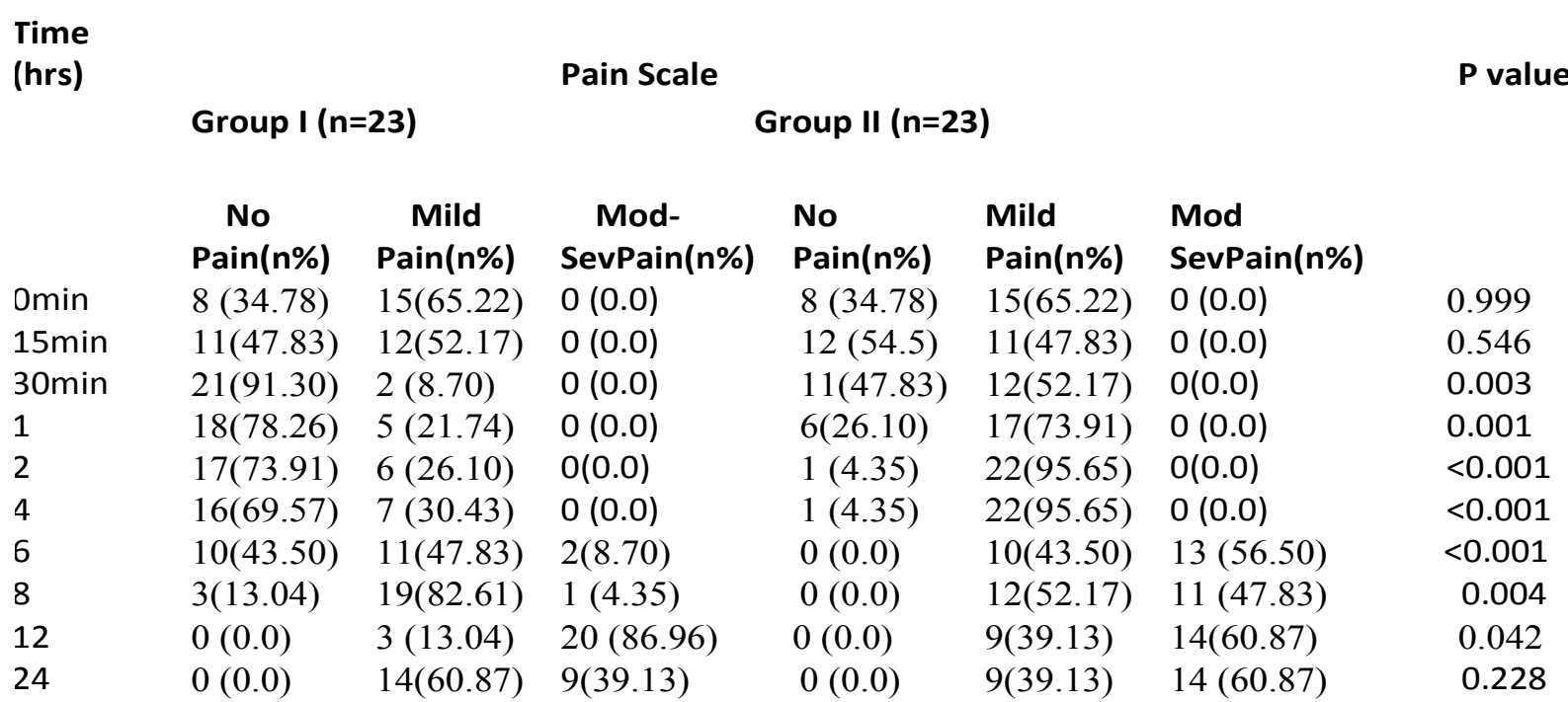

\author{
Chi square \\ No pain =OPS 0 \\ Mild pain: OPS 1-4 \\ Moderate to severe pain: OPS $\geq 5$
}

The Objective Pain Scores are shown in Table III. There was no statistically significant association between the groups' OPS at 0 and 15 minutes $(\mathrm{p}=0.999$ and 0.650 respectively) At 30 minutes, 21 (91.3\%) of patients in group I felt no pain (OPS $=0)$ compared to $11(47.8 \%)$ of group II with no pain while $2(8.7 \%)$ patients in group I and $12(52.2 \%)$ patients in group II felt mild pain. This association was statistically significant $(\mathrm{p}=$ $0.003)$. At the first hour, 18 (78.3\%) of group I patients felt no pain compared to $6(26.1 \%)$ of group II while $5(21.7 \%)$ patients in group I and $17(73.9 \%)$ patients in group II felt mild pain. There was a statistically significant difference $(p=0.001)$. At the second hour, 17 $(73.9 \%)$ of group I patients felt no pain compared to 1 $(4.4 \%)$ of those in group II while $6(26.1 \%)$ of group I and $22(95.7 \%)$ of group II felt mild pain. This was statistically significant $(\mathrm{p}<0.001)$. At $4^{\text {th }}$ hour, $16(69.6 \%)$ of group I felt no pain compared to $1(4.4 \%)$ of group II. Seven $(30.4 \%)$ of group I patients and 22 (95.7\%) of group II felt mild pain. This was also statistically significant $(\mathrm{p}<0.001)$. At 6 th hour, $10(43.5 \%)$ patients of group I felt no pain,11(47.8\%) felt mild pain (OPS $=1-4)$ and $2(8.7 \%)$ patients felt moderate to severe patient while patients in group II felt different levels of pain, $10(43.5 \%)$ felt mild pain and $13(56.5 \%)$ felt moderate to severe pain (OPS $=5-10)$. This was statistically significant $(\mathrm{p}<0.001)$. At 8 th hour, $3(9.1 \%)$, $19(86.4 \%), 1(4.4 \%)$ of group I had no pain, mild and moderate to severe pain respectively while $12(52.2 \%)$ and $11(47.9 \%)$ of group II had mild pain and moderate to severe pain respectively. This association was also statistically significant $(\mathrm{p}=0.004)$. At the 12th hour, 3 $(13.0 \%)$, and $20(86.9 \%)$ of group I felt mild pain and moderate to severe pain respectively while 9 (39.1\%), and $13(60.9 \%)$ patients of group II felt mild pain and moderate to severe pain respectively. There was also a statistical difference with p-value of 0.042 . At the 24 th hour, 14 (60.9\%), 9 (39.1\%) of group I had, mild pain and moderate to severe pain respectively while in group II $9(39.1 \%)$ and $14(60.9 \%)$ patients felt, mild pain and moderate to severe pain respectively. There was no statistical difference with $\mathrm{p}$-value of 0.228 
Table IV: Mean time interval to rescue analgesic request from study drug administration and mean dose of rescue analgesia in 24 hours

\begin{tabular}{|c|c|c|c|c|}
\hline Parameter & $\begin{array}{l}\text { Group 1(23) } \\
\text { Mean } \pm \text { SD }\end{array}$ & $\begin{array}{l}\text { Group } 11 \\
\text { mean } \pm \text { SD }\end{array}$ & P-value & LOS \\
\hline $\begin{array}{l}\text { Time to } \\
1^{\text {st }} \text { analgesic } \\
\text { request(min) }\end{array}$ & $667.73 \pm 24.66$ & $371.27 \pm 60.48$ & $<0.001$ & $\mathbf{S}$ \\
\hline $\begin{array}{l}\text { Dose of } \\
\text { rescue } \\
\text { analgesia(mg) } \\
\text { in } 24 \mathrm{hrs}\end{array}$ & $19.35 \pm 5.42$ & $27.32 \pm 5.84$ & $<0.001$ & $\mathbf{S}$ \\
\hline
\end{tabular}

\section{Student's t- test}

LOS- level of significance

Table IV shows the mean time to first analgesic request and the average dose of rescue analgesic (intravenous pentazocine) consumed in 24 hours. The mean time to first analgesic requirement was longer in group I. It was approximately $667.73 \pm 24.7$ (11.12 hours) in group I and $371.27 \pm 60.5$ (6.2 hours) in group II. This showed marked significant difference $(\mathrm{p}<0.001)$ when compared using Student's t-test. The mean rescue analgesic consumption in 24 hours postoperatively was lower in group I (19.35 $\pm 5.4 \mathrm{mg})$ than in group II $(27.32 \pm 5.8 \mathrm{mg})$. There was a significant difference with a p-value $<0.001$.

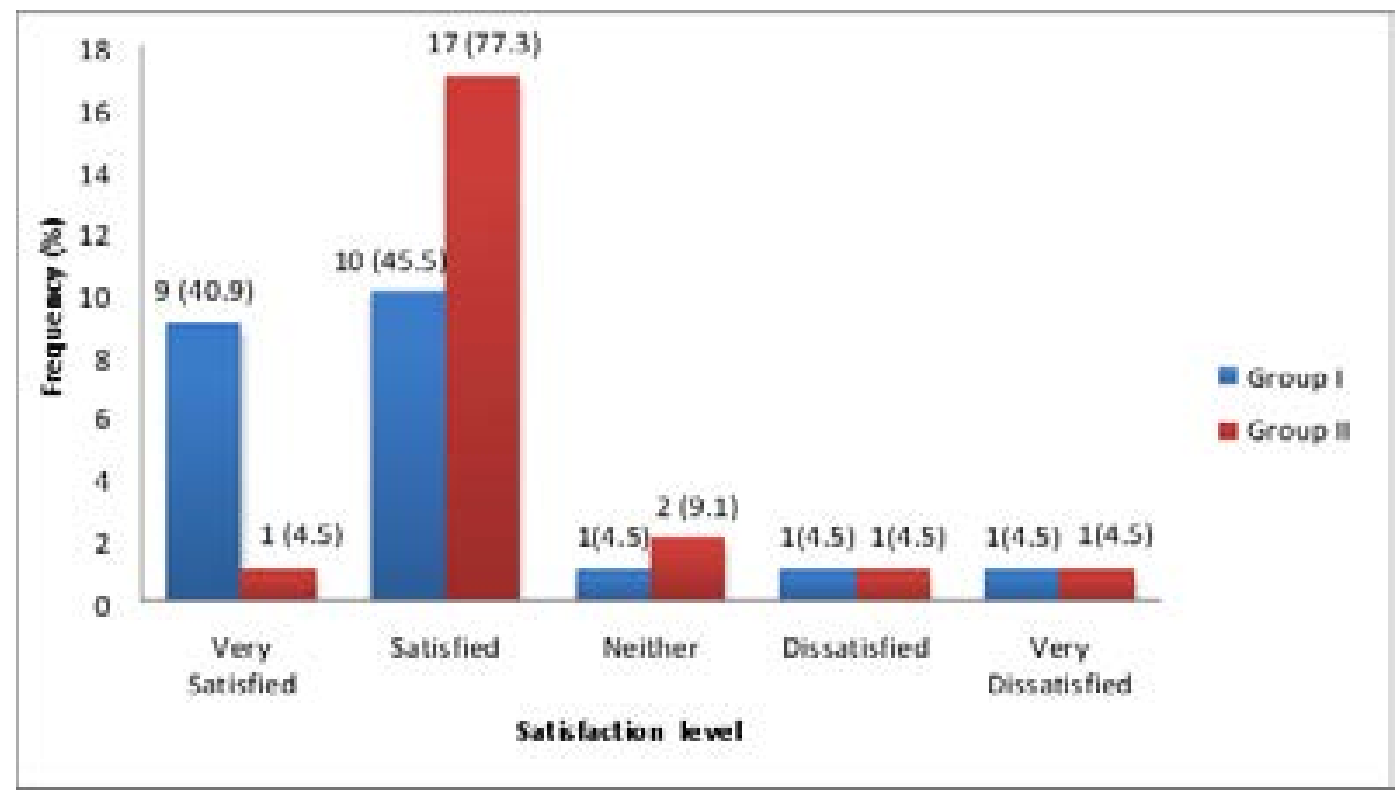

Figure 1: Parent's satisfaction with analgesia 
Two patients in group I vomited once at the 4th hour and 6th hour respectively. There was no other reported side effect. Figures 1 showed the intraoperative haemodynamic parameters.

These parameters which included pulse rate, systolic blood pressure, diastolic blood pressure and mean arterial pressure were measured at 5 minutes' intervals. They were identical in both groups without much variation. There was a slight rise in the pulse rate of group 1at the 50th minute which settled again to near baseline within five minutes. The systolic blood pressure in group 1 was slightly higher than group 11 but clinically insignificant. Also, the mean arterial pressure of group 1was marginally higher than that of group 11 throughout the procedure though, clinically insignificant

Figure 3 showed the level of satisfaction by parent/ guardian of patients. In group I, nine parents (40.9\%) were very satisfied, 10 parents $\{45.5 \%\}$ were satisfied, one parent $\{4.5 \%\}$ was neither satisfied nor dissatisfied, one each showed dissatisfaction and very dissatisfied respectively. In group II, one parent $\{4.5 \%\}$ was very satisfied, $17\{77.3 \%\}$ were satisfied, two $\{9.1 \%\}$ were neither satisfied nor dissatisfied while one (4.5\%) each showed dissatisfaction and very dissatisfied respectively

\section{Discussion}

This study showed that subcutaneous ketamine plus plain bupivacaine infiltration provided better and longer duration of analgesia than local infiltration of plain bupivacaine alone in the immediate postoperative period after unilateral inguinal herniotomy in children. There has been an emphasis on a multimodal approach to pain management with improved patient's satisfaction and safety ${ }^{7}$ which this study has further proved.

A longer time to first analgesic request in the postoperative period is an evidence of better pain control. In this study, subcutaneous ketamine in addition to surgical wound site infiltration of plain bupivacaine led to longer time to first analgesic request. The reason for this observed finding is the analgesic property of ketamine even at low doses and the slow release of ketamine into the circulation from the subcutaneous route. Semple et $\mathrm{al}^{8}$ had demonstrated the analgesic properties of different doses of ketamine added to caudally administered bupivacaine for postoperative analgesia following infra-umbilical surgery with prolonged duration of analgesia compared to bupivacaine alone. A similar finding was also reported by Odes and colleaques $^{9}$ in a study where they administered ketamine and ropivacaine combination for caudal block in contrast to subcutaneous ketamine and bupivacaine infiltration used in this study. The patients in ketamine plus ropivacaine group had longer time to first analgesic request against ropivacaine alone group. Ketamine-ropivacaine group in addition also had a significant reduction in pain scores and decreased analgesic consumption with minimal side effect in the first 24 hours post-operatively. A similar result is also seen in the work of Sidiqui and coworkers where they used ketamine and bupivacaine in a caudal block for herniorrhaphy ${ }^{10}$. Kushimo and co-workers, however, reported a longer pain-free period in their patients who received local infiltration with bupivacaine following herniotomy ${ }^{11}$ compared to our study. Our patients had a pain free period of 6.2 hours (371.3minutes) for those who received only surgical wound site plain bupivacaine infiltration and 11.12 hours (667.7 minutes) for patients who subcutaneous ketamine and surgical wound site infiltration with plain bupivacaine. The reason for this observation is difficult to explain, however, the long hours of pain-free period achieved with subcutaneous ketamine plus infiltration of the surgical site with plain bupivacaine is clinically significant.

Our findings are also comparable to the observations by Jha et al $^{12}$ who noted that subcutaneous ketamine plus bupivacaine infiltration provided a longer favourable pain score state of up to 12 hours with a low pain score of less than 4 and also lower analgesic demand in patients that had palate repair under general anaesthesia. In addition, Honamand and colleaques ${ }^{13}$ infiltrated peritonsils of their patients with doses of ketamine and found lower pain scores in the ketamine groups when compared with the control group over 24 hours after surgery. These studies although, were conducted on different types of surgery, where pain intensities may vary from pain of herniotomy, showed that ketamine enhanced analgesic duration and effect of bupivacaine which were similar to our study. Javid and coworkers ${ }^{14}$ also corroborated the efficacy of low dose subcutaneous ketamine in achieving low and favourable pain scores in a study. They observed lower pain scores in all the ketamine groups compared to the control group. They also noted that the pain scores in ketamine groups were similar in the intravenous ketamine group and in the ketamine infiltration group up to the 6th hour which was the last assessment period in their study.

Total postoperative analgesic consumption is also an index of efficacy and quality of analgesia. In this study, the postoperative analgesic consumption was significantly lower in group I who received multimodal an- 
algesic therapy than in group II. This is similar to the finding of Alireza $\mathrm{K}$ et $\mathrm{al}^{15}$ where they observed that ketamine plus bupivacaine group received the lowest rescue analgesic over 24 hours compared to other groups. In addition, Ozyalcin et $\mathrm{al}^{16}$ noted that low dose ketamine decreased postoperative analgesic consumption to a significant level without any side effect due to its analgesic effectiveness along with a proven harmony with bupivacaine.

Despite the well-known side effects of ketamine such as hallucination, drowsiness, vomiting, sedation and excessive salivation, the dose of ketamine used in this study was well tolerated. This could be due to the low dose and slow release of the subcutaneously deposited ketamine into the systemic circulation. Javid et $\mathrm{al}^{14}$ also noted minimal side effect in their study. This low incidence of side effect following subcutaneous low dose ketamine is thought to be due to the plasma level of ketamine less than $150 \mathrm{ng} / \mathrm{ml}$.

The high number of parents/guardians satisfaction was an indication of adequate anaesthesia and analgesia received by the patients with minimal side effects. Guardians/ parents in the combination group showed higher satisfaction probably because of longer time to first analgesic request in this group. It could also be due to the lower postoperative analgesic consumption the patients in this group received. Early ambulation and early transition to oral intake patients in this group were probably exposed to could have contributed to this higher satisfaction.

\section{Study limitation}

The age range of patients studied (3-7years) necessitated the evaluation of both preverbal and verbal children, introducing some degree of non-uniformity in the study sample.

Notwithstanding, this age range represents the highest incidence of presentation for herniotomy, hence the compelling need to study this population.

\section{Conclusion}

This study revealed that the combination of subcutaneous ketamine $[0.5 \mathrm{mg} / \mathrm{kg}]$ plus surgical wound site plain bupivacaine infiltration $[1 \mathrm{mg} / \mathrm{kg}$ of $0.25 \%$ ] provided superior quality of postoperative analgesia than bupivacaine alone for herniotomy with minimal side effect.

\section{References}

1. Usang UE, Sowande OA, Adejuyigbe O, Bakare TI, Ademuyiwa OA. Day case inguinal hernia surgery in
Nigerian Children: Prospective study. Afri J Paediatr Surg 2008; 5:76-78.

2. Seyed AHJ, Sadegh SP, Seyedeh MHV, Amir J. Effects of Suppository Acetaminophen, Bupivacaine Wound Infiltration and Caudal Block with Bupivacaine on Post- Operative Pain in Pediatric Inguinal Herniorhaphy. Anesth Pain Med 2012;1 (4): 243-

3. Moiniche S, Mikkelsen S, Wetterslev J, Dahl JB. A qualitative systematic review of incisional local anaesthesia for post-operative pain relief after abdominal operations. BrJ Anaesth 1998;81(3):377-383

4. Whiteman A, Bajaj S, Hasan M. Novel techniques of local anaesthetic infiltration. Contin Educ Anaesth Crit Care Pain 2011; 11(5):167-171.

5. Bazin V, Bollot J, Asehnoune K, Roquilly A, Guilland $\mathrm{C}$ et al. Effect of perioperative intravenous low dose of ketamine on post-operative analgesia in children. Eur J Anaesth 2010; 27(1):47-52.

6. Behaeen K, Soltanzadeh M, Nesioonpour S, Ebadi A,Olapour A, et al. Analgesic effect of low dose subcutaneous ketamine administration before and after caesarian section. Iran Red Crescent Med J 2014;16(3): 155-160

7. Kehlet H, Dahl JB. The value of multimodal or balance analgesia in the postoperative pain treatment. $A n$ esth Analg 1993; 77: 1048-1056.

8. Semple D, Findlow D, Aldridge LM, Doyle E. The optimal dose of ketamine for caudal epidural blockade in children. Anaesthesia 1996; 51(12):1170-1172.

9. Odes R, Erhan OL, Demirei M, Goksu H. Effect of ketamine added to ropivacaine in pediatric caudal block. Agri 2010; 22:53-60.

10. Siddiqui Q, Chowdhury E. Caudal analgesia in Paediatrics. Acomparison between bupivacaine and ketamine. The internet J Anaesthesiol 2005;(11)1

11. Kushimo OT, Bode CO, Adedokun BO, Desalu I. Incisional infiltration of bupivacaine for post-operative analgesia in children. Afri J Anaesth Int Care 2001; 4(1) :13-15

12. Jha AK, Bhardwaji N, Yaddanapudi S, Shamma RK, Mahajan JK. A Randomised study of surgical site infiltration with bupivacaine or ketamine for pain relief in children following cleft palate repair. Paediatr Anesth 2013; 23: 401-406.

13. Honamand A, Safavi MR, Jamshidi M. The preventive analgesic effect of preincisional infiltration of two low doses of ketamine for post-operative pain relief in children following adenotonsillectomy.A randomised double blind placebo controlled study. Paeditr Anaesth 2008; 18:508-514. 
14. Javid MJ, Hajijafari M, Hajipour A, Makarem J, Khazaeipour Z. Evaluation of low dose ketamine in post tonsillectomy pain relief: A randomized trial comparing intravenous and subcutaneous ketamine in pediatrics. Anesth Pain 2012, 2(2):85-89

15. Alireza K, Mojan R, Mohammad SF, Seyedah AM, Hamid $G$ et al. The effect of local injections of bupivacaine plus ketamine, Bupivacaine alone and placebo on reducing postoperative anal fistula pain. A randomized clinical trial. The Sci World J 2014; (2014): 6-12.
16. Ozyalcin NS, Yucel A, Camlica H, Dereli N, Anderson OK et al. Effect of pre-emptive ketamine on sensory changes and post-operative pain after thoracotomy: Comparison of epidural and intramuscular routes. $\mathrm{Br} \mathrm{J}$ Anaesth 2004; 93: 356-361

17. Grant IS, Nimmo WS, Clements JA. Pharmacokinetics and analgesic effects of i.m. and oral ketamine. $\mathrm{Br}$ J Anaesth. 1981;53(8):805- 10

18. Edomwonyi NP, Egwakide EA. Post-operative analgesia in children. Caudal versus local. Afri J Anaesth Int care 2005; 6 (1):1-4 